International Journal of Agriculture, Environment and Bioresearch

Vol. 5, No. 02; 2020

ISSN: $2456-8643$

\title{
VASORELAXANT EFFECT OF THE ALKALOID 1-0-BENZOYLNAPPELINE ON ISOLATED RAT THORACIC AORTA
}

\author{
Adilbay Esimbetov $^{1}$, Abdisalim Zaripov ${ }^{1}$, Sirojiddin. Omonturdiev ${ }^{2}$, Mukhlis Sultankhodjaev $^{3}$ and Pulat \\ Usmanov $^{2}$ \\ ${ }^{1}$ Karakalpak State University named after Berdakh, Nukus, Uzbekistan \\ ${ }^{2}$ National University of Uzbekistan, Tashkent, Uzbekistan \\ ${ }^{3}$ Institute of Chemistry of Plant Substances, Uzbek Academy of Sciences, Tashkent, Uzbekistan
}

https://doi.org/10.35410/IJAEB.2020.5498

\begin{abstract}
To investigate the possible mechanisms of vasorelaxant action of 1-O-benzoylnappeline (1-0$\mathrm{BN}$ ), a diterpenoid alkaloid napelline derivative.: The vasorelaxant activity of 1-0-BN was examined using standard organ bath techniques and endothelium intact rat aortic rings, precontracted by phenylephrine (PE) or by a high $\mathrm{KCl}(50 \mathrm{mM})$. 1-O-BN induced vasorelaxation, in rat aortic rings, precontracted by both $\mathrm{PE}$ and high $\mathrm{KCl}$, in a concentrationdependent manner and with almost equal effectiveness. 1-O-BN significantly attenuated $\mathrm{CaCl} 2$ induced contractions in a $\mathrm{Ca} 2$ +-free medium containing $\mathrm{KCl}(50 \mathrm{mM})$. Furthermore, the vasorelaxant potency of 1-O-BN significantly reduced in the presence of verapamil. 1-O-BN significantly reduced the transient contractions induced by $\mathrm{PE}$ or caffeine in $\mathrm{Ca} 2+-$ free medium. The vasorelaxant effect of 1-O-BN progressively reduced with an elevation of $\mathrm{KCl}$ concentration (from $20 \mathrm{mM}$ to $100 \mathrm{mM}$ ) and markedly attenuated by glibenclamide but not significantly affected by TEA, $\mathrm{BaCl} 2$, and 4-AP. Together, the results of the present study indicate that activation of KATP channels may play an important role in 1-O-BN induced vasorelaxation. The suppression of contractions induced by high $\mathrm{KCl}$ and by $\mathrm{PE}$, in calcium-free medium, suggest that the inhibition of $\mathrm{Ca} 2+$ influx through voltage-dependent $\mathrm{Ca} 2+$ channels and $\mathrm{Ca} 2+$ release from intracellular stores also may be involved in the vasorelaxant effect of 1-O-BN.
\end{abstract}

Keywords: Diterpenoid alkaloid, rat aorta, vascular smooth muscle cells, vasorelaxation, ion channels.

\section{INTRODUCTION}

Diterpenoid alkaloids isolated from Aconitum and Delphinium plant species are compounds with a broad range of bioactivity which are of considerable interest in the search for new lead compounds for developing novel drugs for the treatment of cardiovascular diseases (Lee, 2001; Tirapelli et al., 2010; Guzman and Molina, 2018). In recent years a great deal of attention has focused on the diterpenoid alkaloids with antispasmodic activity as the most promising candidates for yielding compounds with potential hypotensive effect due to their pronounced vasorelaxant action (Tabassum and Ahmad, 2011; Li et al., 2017; Periera, 2017). Recently it was reported that diterpenoid alkaloid napelline isolated from Aconitum monticola and its derivative 1-O-benzoylnappeline exhibit potent spasmolytic activity (Dzhakhangirov et al, 2007). These 
Vol. 5, No. 02; 2020

ISSN: $2456-8643$

authors showed that the modification of the structure of the napelline by replacing the hydroxyl group with the benzoyl group at $\mathrm{C}-1$ in the diterpene skeleton markedly enhances antispasmodic activity studied on isolated rat small intestines using the barium-chloride contraction model. Based on data obtained authors suggested that the spasmolytic effect of 1-O-benzoylnappeline is associated with its relaxant activity exerted through inhibition of the various types of ion channels (Dzhakhangirov et al, 2013). However, the detailed description of the relaxant effect of 1-O-benzoylnappeline and the precise mechanism of such action is still not established to date. In the previous study, we had found that 1-O-benzoylnappeline (1-O-BN) possesses a marked relaxant activity, evaluated on rat aortic rings precontracted with high $\left[\mathrm{K}^{+}\right]$and phenylephrine (Begdullaeva et al., 2011). Therefore, the objective of the present study was to further characterize the effects of 1-O-benzoylnappeline on the contraction of rat aortic rings and to investigate its possible mechanism of vasorelaxant action.

\section{MATERIALS AND METHODS}

Animals and aortic rings preparation. Male albino rats weighing 200-250 g were anesthetized with sodium pentobarbital and killed by decapitation. All animal care and experimental procedures were approved by the Committee for Animal Experiments of Institute of Biophysics and Biochemistry at the National University of Uzbekistan. The thoracic aorta was quickly removed, cleaned of adherent connective tissues and cut into rings 3-4 mm in length. The aortic rings were mounted in a $5 \mathrm{ml}$ organ bath contained Krebs solution of the following composition (mM): $\mathrm{NaCl} 118, \mathrm{KCI} 4.75, \mathrm{NaHCO}_{3} 25, \mathrm{MgSO}_{4} 1.2, \mathrm{CaCI}_{2} 1.8, \mathrm{KH}_{2} \mathrm{PO}_{4} 1.2$ and glucose 11.1, $\mathrm{pH}$ 7.4. Krebs solution was maintained at $37^{\circ} \mathrm{C}$ and bubbled with $95 \% \mathrm{O}_{2}-5 \% \mathrm{CO}_{2}$ gas mixture. Aortic rings were mounted by means of two stainless steel wire hooks inserted through the lumen of the ring.

During the experiments, while working with experimental animals, International principles of the Helsinki Declaration and the rules of human attitudes towards animals were completely followed. Ethical commitee permission (No. 2).

Vascular tension recording. The changes in isometric tension were recorded (under a resting tension of $1 \mathrm{~g}$ ) using force-displacement transducer FT03 (Grass Instrument Co. MA, USA) connected to a force transducer amplifier and stored in a computer. All experiments were performed on endothelium intact aortic rings. Endothelial integrity was evaluated from a degree of relaxation using acetylcholine $(10 \mu \mathrm{M})$ while under the contractive activity effect induced by phenylephrine $(10 \mu \mathrm{M})$. Each preparation was allowed to equilibrate for at least 60 min prior to initiation of experimental procedures and during this period the incubation media were changed every $15 \mathrm{~min}$.

Experimental procedures. After equilibrations, the following experimental procedures were performed: At first, to evaluate the vasorelaxant activity of 1-O-BN aortic rings were precontracted by $\mathrm{KCl}(50 \mathrm{mM})$ or phenylephrine $(\mathrm{PE} 1 \mu \mathrm{M})$ and than alkaloids were added cumulatively to obtain a concentration-response curve. To investigate the roles of extracellular $\mathrm{Ca}^{2+}$ influx in the 1-O-BN-induced vasorelaxation the aortic rings were exposed to $\mathrm{Ca}^{2+}$-free Krebs solution for 20 min prior to pre-contraction with $\mathrm{KCl}(50 \mathrm{mM})$ and then $\mathrm{Ca}^{2+}$ was added 
Vol. 5, No. 02; 2020

ISSN: $2456-8643$

cumulatively to obtain a concentration-response curve in the presence of alkaloids. To clarify the role of voltage-dependent $\mathrm{Ca}^{2+}$ channels in the 1-O-BN -induced vasorelaxation the aortic rings were incubated in normal Krebs solution containing verapamil $(1 \mu \mathrm{M})$ for $30 \mathrm{~min}$ prior to precontraction with $\mathrm{KCl}(50 \mathrm{mM})$ and then alkaloid were added to evoke relaxation. To define a possible effect of alkaloids on the $\mathrm{Ca}^{2+}$ release from intracellular stores aortic rings were incubated in $\mathrm{Ca}^{2+}$-free solution containing verapamil $(10 \mathrm{mM})$ for $30 \mathrm{~min}$ prior to precontraction with PE $(1 \mu \mathrm{M})$ or caffeine $(30 \mathrm{mM})$ and then alkaloids were added to evoke relaxation. Since in $\mathrm{Ca}^{2+}$-free solution, caffeine-induced a maximal contraction at $25^{\circ} \mathrm{C}$ in these experiments the temperature of maintained at $25^{\circ} \mathrm{C}$. To explore the role of $\mathrm{K}^{+}$channels in the vasorelaxant action of 1-O-BN its effects at a various external concentration of $\mathrm{KCl}$ (replaced by equimolar $\mathrm{NaCl}$ ) was examined. In addition in order to identify the specific types of $\mathrm{K}^{+}$channels involved in the vasorelaxant action of 1-O-BN its effects were evaluated in the presence of a nonselective $\mathrm{K}^{+}$ channel blocker tetraethylammonium (TEA), the voltage-dependent $\mathrm{K}^{+}$channel blocker 4aminopyridine (4-AP), inward rectifying $\mathrm{K}^{+}$channel blocker $\left(\mathrm{BaCl}_{2}\right)$ and ATP-sensitive $\mathrm{K}^{+}$ channel ( $\mathrm{K}_{\mathrm{ATP}}$ ) blocker glibenclamide (Glib).

Drugs and solutions. The following drugs were used: acetylcholine, phenylephrine, caffeine, verapamil, N-nitro-L-arginine methyl ester, indomethacin, tetraethylammonium chloride, 4aminopyridine, barium chloride, glibenclamide, nicorandil all obtained from Sigma Ltd Co., (St. Louis, MO, USA). 1-O-benzoylnappeline was the generous gift of Dr. M. Sultankhodjaev (Institute of the Chemistry of Plant Substances, Tashkent, Uzbekistan). All drugs were dissolved in distilled deionized water to prepare stock solutions (except glibenclamide and nicorandil which were dissolved in dimethylsulfoxide (DMSO), and indomethacin and verapamil was dissolved in ethanol), and further dilutions were made in Krebs' solution. Drug concentrations are expressed as final molar concentrations in the organ bath.

Statistical analysis. All data are expressed as means \pm S.E.M. The concentration of the alkaloids evoking $50 \%$ of maximal relaxation $\left(\mathrm{IC}_{50}\right)$ and the value of maximal relaxation (Emax) (expressed as a percentage of a previous contraction induced by the contractile agent.) were calculated using a non-linear iterative curve-fitting procedure. Differences between means were statistically compared using Student's t-test and/or one-way ANOVA. The significance level considered in all tests was 0.05 . All values were obtained using Graph-Pad Prism ${ }^{\circledR} 5.01$ software (GraphPad Software Inc., USA).

\section{RESULTS AND DISCUSSION}

\section{Results}

The vasorelaxant effect of 1-O-BN on $\mathrm{KCl}$ and $\mathrm{PE}$-induced rat aortic ring contraction. To characterize the vasorelaxant effect of 1-O-BN, in the first the concentration-response curves were determined in rat aortic rings precontracted with $\mathrm{KCl}(50 \mathrm{mM})$ or $\mathrm{PE}(1 \mu \mathrm{M})$. As shown in Figure $11-\mathrm{O}-\mathrm{BN}$ in a concentration-dependent manner relaxed $\mathrm{KCl}$-induced contractions of aortic rings. The maximal relaxation (Emax) of $81.1 \pm 3.5 \%(n=6)$ was obtained when the aortic ring was treated with $100 \mu \mathrm{M}$ of $1-\mathrm{O}-\mathrm{BN}$. The $\mathrm{IC}_{50}$ (the concentration to produce a $50 \%$ maximal relaxation) value for 1-O-BN obtained in these experimental conditions was 12,7 $\mu \mathrm{M}$. Similarly, 
1-O-BN also in a concentration-dependent manner relaxed PE-induced contractions of aortic rings with a maximal effect of $75.4 \pm 3.1 \%$ and an $\mathrm{IC}_{50}$ value of $21.4 \mu \mathrm{M}$ (Figure 1).

From the obtained $\mathrm{IC}_{50}$ values it can be concluded that 1-O-BN produced a more potent relaxation effect on $\mathrm{KCl}$-that $\mathrm{PE}$-induced contraction in aortic rings. These relaxant effects of 1$\mathrm{O}-\mathrm{BN}$ on aortic rings precontracted with both $\mathrm{KCl}$-and $\mathrm{PE}$ were not significantly attenuated by removal of the endothelium or in the presence of L-NAME $(50 \mathrm{mM})$ and indomethacin. These results suggest that 1-O-BN induced vasorelaxation is not endothelium-dependent and mainly mediated by direct activation of relaxation mechanisms of vascular smooth muscle cells.

The role of voltage-gated $\mathrm{Ca}^{2+}$ channels in 1-O-BN-induced vasorelaxation. In this set of experiments, the effect of 1-O-BN on the concentration-response curve to $\mathrm{CaCl}_{2}$ in aortic rings was investigated. As shown in Figure 2, A cumulative addition of $\mathrm{CaCl}_{2}$ to $\mathrm{Ca}^{2+}$-free Krebs solution, containing $50 \mathrm{mM} \mathrm{KCl}$, induced a concentration-dependent increase of contraction of aortic rings. Pretreatment of aortic rings with 1-O-BN $(100 \mu \mathrm{M})$ significantly reduced the potency of contractile responses to $\mathrm{CaCl}_{2}$ [Figure 2, A]. In these conditions in the presence of $100 \mu \mathrm{M} 1-\mathrm{O}-\mathrm{BN}$, the maximal response to $\mathrm{CaCl}_{2}$ was reduced by $83.8 \pm 4.1 \%$ suggesting that this effect of the alkaloid is possibly mediated through the inhibition of L-type $\mathrm{Ca}^{2+}$ channels. To clarify this further, the effect of $1-\mathrm{O}-\mathrm{BN}$ on the concentration-response curve to $\mathrm{CaCl}_{2}$ was compared with those of verapamil, an L-type voltage-gated $\mathrm{Ca}^{2+}$ channel blocker. As can be seen from Figure 2, A verapamil $(1 \mu \mathrm{M})$ significantly reduced the contractile responses to $\mathrm{CaCl}_{2}$ with the maximal reduction of contraction by $95 \pm 3.6 \%$, indicating that it produced more potent inhibition of $\mathrm{CaCl}_{2}$-induced contraction than 1-O-BN. In addition experiments with the combined use of 1-O-BN and verapamil showed that in the presence of verapamil the vasorelaxant effect of the alkaloid is significantly reduced. In these experiments administration of 1-O-BN $(100 \mu \mathrm{M})$ on top of verapamil $(0.1 \mu \mathrm{M})$, concentration equal to its $\mathrm{IC}_{50}$ value reduced the $\mathrm{KCl}$-induced contraction of aortic rings further from $50 \pm 4.2 \%$ to $33.9 \pm 3.3 \%$ (Figure 2, B).

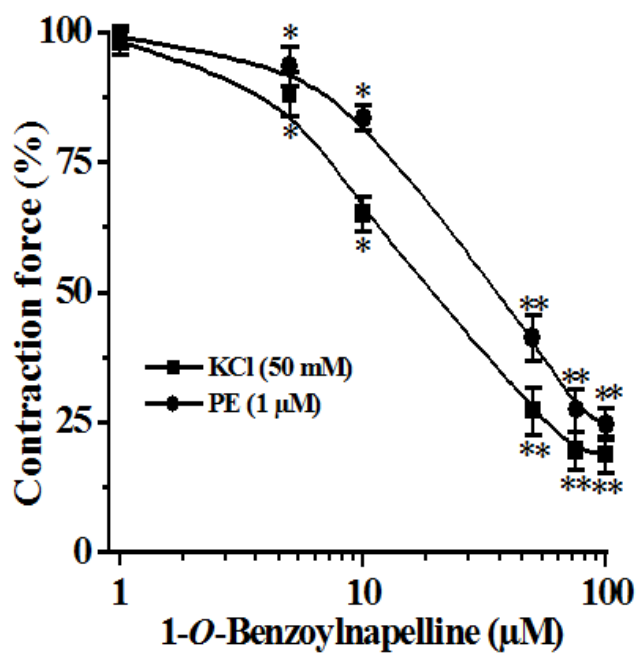


Figure 1. Concentration-dependent effects of $1-0-\mathrm{BN}$ in endothelium-intact rat aortic rings. Concentration-response curves to 1-0-BN were determined in rat aortic rings pre-contracted with phenylephrine $(\mathrm{PE}, 1 \mu \mathrm{M} ; \bullet)$ and $\mathrm{KCl}(50 \mathrm{mM} ; \boldsymbol{-})$. Data are expressed as a percentage of the contraction induced by $\mathrm{PE}(1 \mu \mathrm{M})$ or $\mathrm{KCl}(50 \mathrm{mM})$. Values are mean $\pm \mathrm{SEM}(\mathrm{n}=6)$. ${ }^{*} \mathrm{P}<0.05$, $* * \mathrm{P}<0.01$, compared with control.
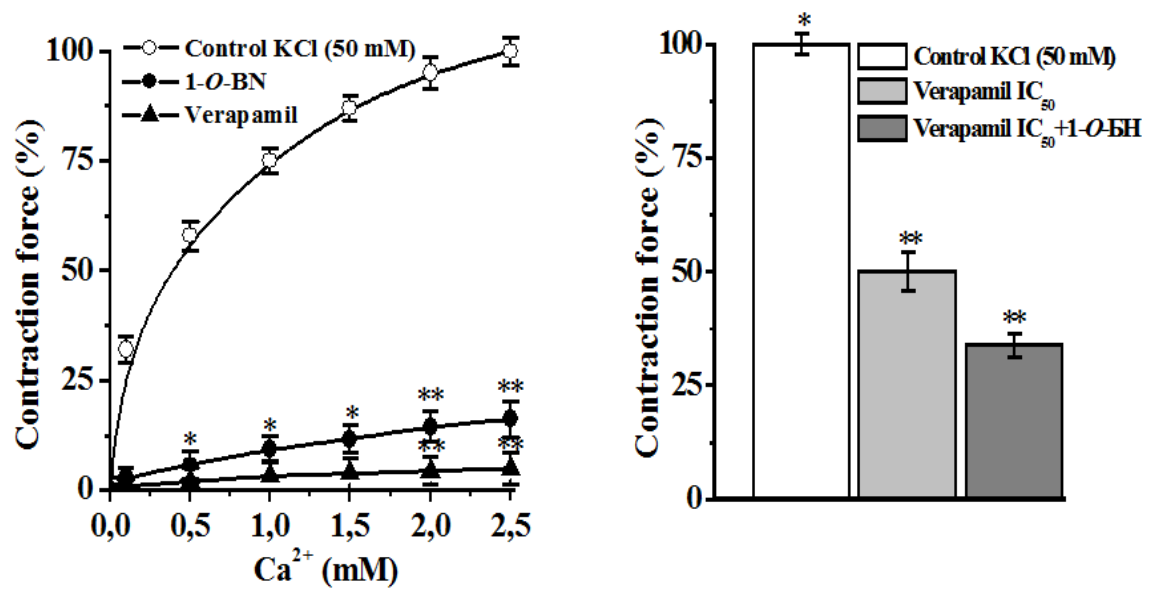

Figure 2. Effect of 1-0-BN and verapamil on the contractile responses to $\mathrm{CaCl}_{2}$ of rat aortic rings (A) and inhibitory action of verapamil on $1-0-\mathrm{BN}$ induced vasorelaxation (B). Acumulative concentration-response curves to $\mathrm{CaCl}_{2}(0-2,5 \mathrm{mM})$ in the aortic rings preincubated in $\mathrm{Ca}^{2+}$-free Krebs solution containing $50 \mathrm{mM} \mathrm{KCl}$. B-effect of verapamil $(0.1 \mu \mathrm{M})$ on vasorelaxation induced by $1-0-\mathrm{BN}$. Values are mean $\pm \mathrm{SEM}(\mathrm{n}=6)$. ${ }^{*} \mathrm{P}<0.05$, **P $<0.01$, compared with control.

Although in these conditions 1-O-BN was able to cause additional relaxation, its relaxant potency in the presence of verapamil is markedly reduced compared with that in the absence of verapamil. Together, these results suggest that inhibition of $\mathrm{Ca}^{2+}$ influx through $\mathrm{L}$-type $\mathrm{Ca}^{2+}$ channels may be involved in the vasorelaxant effect of 1-O-BN. However, additional vasorelaxation produced by 1-O-BN in the presence of verapamil suggests that inhibition of $\mathrm{Ca}^{2+}$ influx through L-type $\mathrm{Ca}^{2+}$ channels is not a major determinant of its vasorelaxant effect.

Effect of 1-O-BN on intracellular $\mathbf{C a}^{2+}$ stores. As can be seen from Figure 3 when extracellular $\mathrm{Ca}^{2+}$ was removed by using a $\mathrm{Ca}^{2+}$-free solution containing EGTA $(1 \mathrm{mM})$, PE $(100 \mu \mathrm{M})$ induced a transient contraction of aortic rings caused by the release of $\mathrm{Ca}^{2+}$ from of sarcoplasmic reticulum (SR). In our experiments pre-treatment of aortic rings with 1-O-BN (100 $\mu \mathrm{M})$ markedly reduced the contractions induced by $\mathrm{PE}$ in a concentration-dependent manner [Figure 3 , A]. In these conditions, the transient contractions induced by PE $(100 \mu \mathrm{M})$ maximally reduced from $68.2 \pm 3.8 \%$ to $19.6 \pm 3.5 \%$. Similarly, in the presence of 1-O-BN $(100 \mu \mathrm{M})$ the transient contractions induced by caffeine reduced from $41.4 \pm 3.2 \%$ to $8.4 \pm 2.9 \%$ (Figure 3, B). 

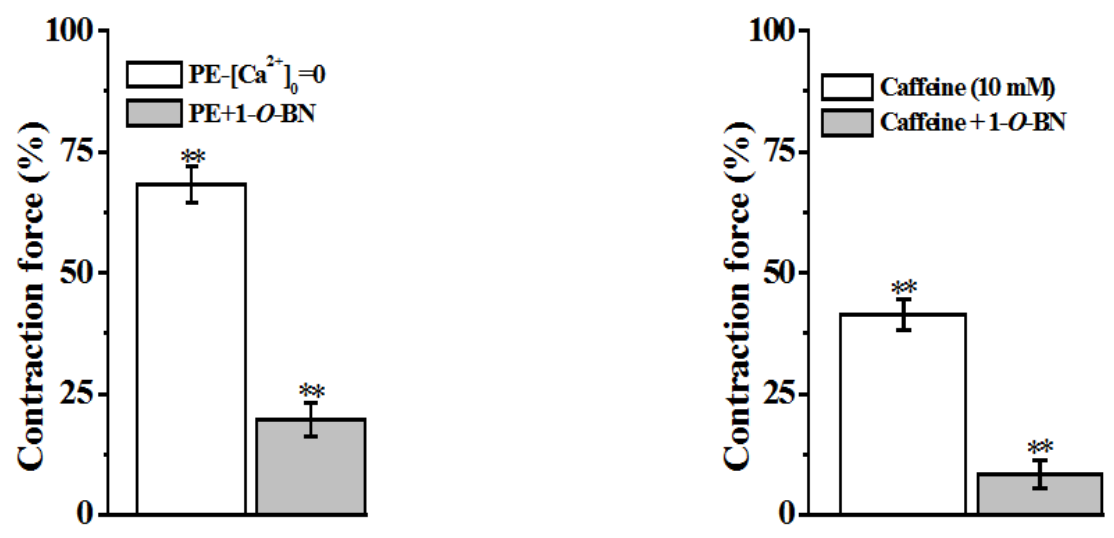

Figure 3. Effect of 1-0-BN on the phenylephrine and caffeine-induced transient contraction of endothelium-intact aortic rings in $\mathrm{Ca}^{2+}$ free Krebs' solution. $\mathrm{A}, \mathrm{B}$ - the aortic rings were precontracted with phenylephrine $(\mathrm{PE}, 1 \mu \mathrm{M})$ and caffeine $(10 \mathrm{mM})$ in $\mathrm{Ca}^{2+}$ free Krebs solution containing EGTA $(100 \mu \mathrm{M})$. Data are expressed as a percentage of the contraction induced by phenylephrine $(1 \mu \mathrm{M})$ or caffeine $(10 \mathrm{mM})$. Values are mean $\pm \mathrm{SEM}(\mathrm{n}=6) . * \mathrm{P}<0.05$, **P $<$ 0.01 , compared with control.

These results indicate that alteration in intracellular calcium stores may also be involved in the vasorelaxation induced by $1-\mathrm{O}-\mathrm{BN}$.

Role of $\mathrm{K}^{+}$channels in 1-O-BN-induced vasorelaxation. In order to investigate the involvement of $\mathrm{K}^{+}$channels in the vasorelaxation induced by 1-O-BN its effect on the contraction of the aortic rings induced by a various concentration of $\mathrm{KCl}$ was examined. Figure 4 shows the concentration-response curves to 1-O-BN obtained in the aortic rings pre-contracted with 20, 50, 80 and $100 \mathrm{mM} \mathrm{KCl}$.

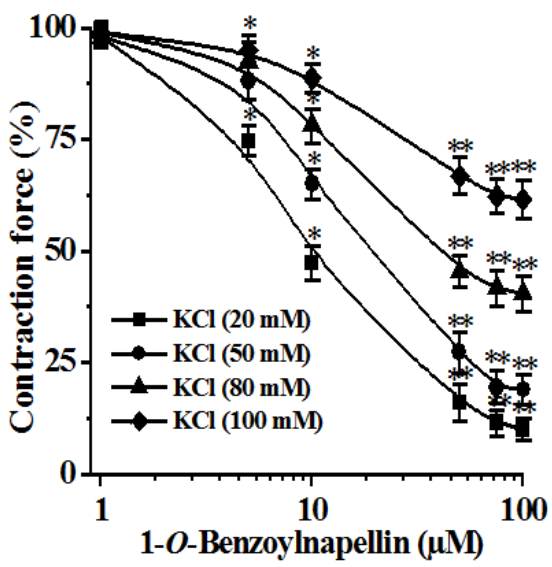


Figure 4. Effect of extracellular concentration of $\mathrm{KCl}$ on concentration-response curves to 1-0$\mathrm{BN}$ in endothelium-intact aortic rings. The concentration-response curves to 1-0-BN were determined in aortic rings pre-contracted with $\mathrm{KCl} 20 \mathrm{mM}(\mathrm{O}), 50 \mathrm{mM}(\bullet), 80 \mathrm{mM}(\mathbf{\Delta})$ and 100 $\mathrm{mM}(\boldsymbol{\bullet})$. Data are expressed as a percentage of the contraction induced by $50 \mathrm{mM} \mathrm{KCl}$. Values are mean \pm SEM $(\mathrm{n}=6) . * \mathrm{P}<0.05, * * \mathrm{P}<0.01$, compared with control.

As can be seen from this figure increasing the concentration of $\mathrm{KCl}$ resulted in significant concentration-dependent reductions of the vasorelaxation induced by 1-O-BN. In these experiments, the maximal vasorelaxation induced by 1-O-BN was reduced from $90 \pm 2.5 \%$ to 36 $\pm 3.9 \%$ and $\mathrm{IC}_{50}$ value increased from $7.8 \mu \mathrm{M}$ to $17.8 \mu \mathrm{M}$ when the aortic rings were precontracted with 20 and $100 \mathrm{mM} \mathrm{KCl}$, respectively. The significant reduction of vasorelaxation induced by 1-O-BN at a high concentration of $\mathrm{KCl}$ indicates that $\mathrm{K}^{+}$channel activation may play an important role in the vasorelaxant action of 1-O-BN.

Determination of the specific types of $\mathrm{K}^{+}$channels involved in the vasorelaxant action of 1O-BN. In these experiments, the vasorelaxant action of 1-O-BN was evaluated in the presence of TEA $(1 \mathrm{mM}), 4-\mathrm{AP}(1 \mathrm{mM}), \mathrm{BaCl}_{2}(0.1 \mathrm{mM})$ and Glib $(50 \mu \mathrm{M})$. Figure 5 shows that the vasorelaxation induced by $1-\mathrm{O}-\mathrm{BN}$ in aortic rings pre-contracted with $20 \mathrm{mM} \mathrm{KCl}$ more strongly inhibited by Glib. In these conditions in the presence of Glib $(50 \mu \mathrm{M})$ maximal vasorelaxation induced by 1-O-BN reduced from $90.0 \pm 2.5 \%$ to $40.7 \pm 2.9 \%$ and $\mathrm{IC}_{50}$ value increased from 7,8 $\mu \mathrm{M}$ to $14,0 \mu \mathrm{M}$. However, the treatment of aortic rings with 4-AP, TEA, and $\mathrm{BaCl}_{2}$ did not significantly modify the vasorelaxation induced by 1-O-BN (Figure 5).

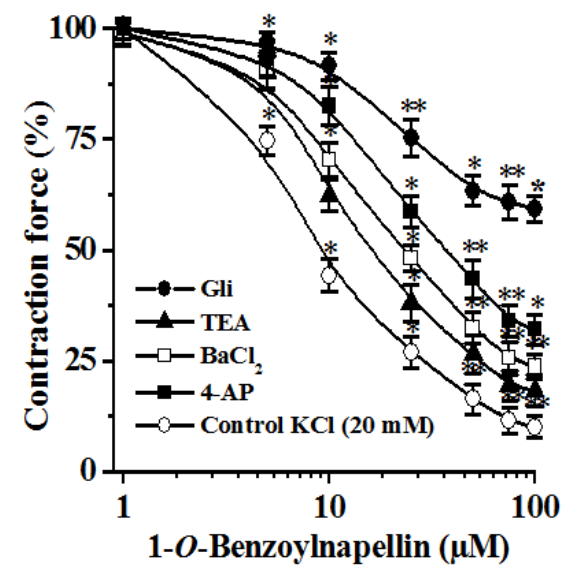

Figure 5. Effect of various K-channel blockers on concentration-response curves to 1-0-BN in endothelium-intact aortic rings. The aortic rings were pretreated with $50 \mu \mathrm{M}$ glibenclamide (Gli; $\bullet$ ), $1 \mathrm{mM}$ 4-AP (-), 0,1 $\mathrm{mM} \mathrm{BaCl}_{2}(\square)$ and $1 \mathrm{mM}$ TEA $(\mathbf{\Delta})$ for $30 \mathrm{~min}$ before construction of 10 -BN concentration-response curves. Data are expressed as a percentage of the contraction induced by $20 \mathrm{mM} \mathrm{KCl}(\mathrm{O})$. Values are mean $\pm \mathrm{SEM}(\mathrm{n}=6)$. $* \mathrm{P}<0.05$, ** $\mathrm{P}<0.01$, compared with control. 
These results suggest that 1-O-BN induced vasorelaxation may be mediated mainly by modulating $\mathrm{K}_{\mathrm{ATP}}$ channels activity. To confirm this further, the effects of glibenclamide on vasorelaxation induced by 1-O-BN and the $\mathrm{K}_{\mathrm{ATP}}$ channels opener nicorandil were compared. In aortic rings pre-contracted with $20 \mathrm{mM} \mathrm{KCl}$ nicorandil and 1-O-BN induced vasorelaxation in a similar concentration-dependent manner (Figure 6).

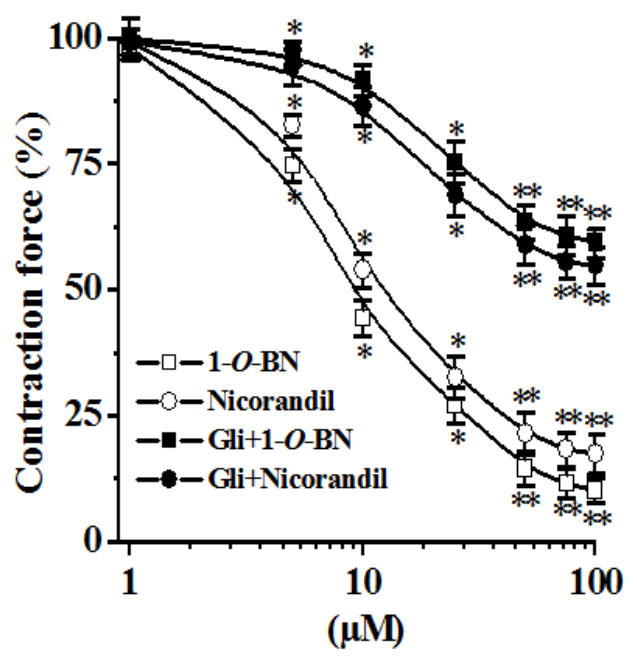

Figure 6. Effect of glibenclamide on concentration-response curves to 1-0-BN and nicorandil in endothelium-intact aortic rings. The concentration-response curves to 1-0-BN and nicorandil were determined in the aortic rings precontracted with $\mathrm{KCl}(20 \mathrm{mM})$ in the absence $(\mathrm{O}, \square)$ or in the presence of glibenclamide $(50 \mu \mathrm{M} ; \bullet$, $\mathbf{\square})$. Data are expressed as a percentage of the contraction induced by $20 \mathrm{mM} \mathrm{KCl}$. Values are mean $\pm \mathrm{SEM}(\mathrm{n}=6)$. $* \mathrm{P}<0.05, * * \mathrm{P}<0.01$, compared with control.

In these conditions, the maximum vasorelaxation induced by nicorandil $(100 \mu \mathrm{M})$ and 1-O-BN $(100 \mu \mathrm{M})$ are $82.7 \pm 3.8 \%$ and $90 \pm 2.5 \%$ with $\mathrm{IC}_{50}$ values of $9.2 \mu \mathrm{M}$ and $7.8 \mu \mathrm{M}$, respectively. These results indicate that the vasorelaxant potency of 1-O-BN is slightly greater than the nicorandil. Figure 6 also shows that pretreatment of aortic rings with Glib $(50 \mu \mathrm{M})$ shifted the concentration-response curve for nicorandil and 1-O-BN to the right in a parallel manner and significantly reduced the maximum of relaxation from $82.7 \pm 3.8 \%$ to $45.2 \pm 3.7 \%$ and from $90 \pm 2.5 \%$ to $40.7 \pm 2.9 \%$, respectively. The $\mathrm{IC}_{50}$ values obtained in these conditions increased from $9.2 \mu \mathrm{M}$ to $21.8 \mu \mathrm{M}$ for nicorandil and from $7.8 \mu \mathrm{M}$ to $14.0 \mu \mathrm{M}$ for 1-O-BN.

\section{Discussion}

The present study demonstrates possible mechanisms by which 1-O-benzoylnappeline (1-O-BN), a diterpenoid alkaloid nappeline derivative, induced vasorelaxation in the rat aortic rings. We found that 1-O-BN potently relaxed aortic rings precontracted by high $\mathrm{K}^{+}$and phenylephrine in a concentration-dependent manner. The vasorelaxant effect of 1-O-BN was most effective in the aortic rings pre-contracted by $\mathrm{KCl}(50 \mathrm{mM})$ that $\mathrm{PE}(1 \mu \mathrm{M})$. This effect of 1-O-BN on aortic rings 
pre-contracted with both $\mathrm{KCl}$ and $\mathrm{PE}$ was not affected by the mechanical removal of the endothelium and in the presence of L-NAME and indomethacin indicating that it is not endothelium-dependent and mainly mediated by direct activation of relaxation mechanisms of vascular smooth muscle cells.

Vascular smooth muscle contractility is regulated by changes in intracellular $\mathrm{Ca}^{2+}$ concentration $\left[\mathrm{Ca}^{2+}\right]_{\mathrm{i}}$ which are controlled by two major mechanisms entry of from the extracellular space, and release of $\mathrm{Ca}^{2+}$ from intracellular stores (Karaki and Weiss, 1984; Berridge, 1997). In smooth muscle, the voltage-dependent L-type $\mathrm{Ca}^{2+}$ channel is the most prominent of $\mathrm{Ca}^{2+}$ entry mechanism which in the response to cell membrane depolarization activates $\mathrm{Ca}^{2+}$ influx leading to an increase in $\left[\mathrm{Ca}^{2+}\right]_{\mathrm{i}}$ and subsequent smooth muscle contraction (Cribbs, 2001; Nelson and Quayle, 1995). In our experiments 1-O-BN markedly reduced aortic ring contraction induced by high extracellular concentration of $\mathrm{KCl}$ suggesting that inhibition of $\mathrm{Ca}^{2+}$ influx through $\mathrm{L}$-type $\mathrm{Ca}^{2+}$ channels may be involved in the vasorelaxant effect of 1-O-BN. This suggestion was confirmed by experiments where 1-O-BN markedly reduced contractile response to $\mathrm{CaCl}_{2}$ in $\mathrm{Ca}^{2+}$-free medium. In addition it was observed that the effect of 1-O-BN on the contractile response to $\mathrm{CaCl}_{2}$ was very similar to that obtained with verapamil. Furthermore, in the combined use of 1-O-BN and verapamil alkaloid was able to cause additional vasorelaxation, but its relaxant potency in the presence of verapamil is significantly reduced. Together these results indicate that blocking the L-type calcium channels involved in the vasorelaxant effect of 1-OBN. However, additional vasorelaxation induced by 1-O-BN in the presence of verapamil suggests that inhibition of $\mathrm{Ca}^{2+}$ influx through L-type $\mathrm{Ca}^{2+}$ channels is not a major determinant of its vasorelaxant effect.

The most important role in maintaining $\mathrm{Ca}^{2+}$ homeostasis in smooth muscle cells plays the sarcoplasmic reticulum (SR) the largest pool of releasable $\mathrm{Ca}^{2+}$ which are involved in the control of smooth muscle contraction and relaxation (Sanders, 2001; Wray and Burdiga, 2010). Therefore, in the present study, we examined the effect of 1-O-BN on the transient contraction of aortic rings induced by phenylephrine and caffeine in $\mathrm{Ca}^{2+}$-free medium. These studies showed that 1-O-BN significantly reduced the contractions induced by phenylephrine and caffeine that provides evidence for the direct inhibition of $\mathrm{Ca}^{2+}$ release from SR. These findings together indicate that 1-O-BN may inhibit the $\mathrm{IP}_{3}$ and/or RyR receptor-dependent $\mathrm{Ca}^{2+}$ release from SR and thus decrease $\left[\mathrm{Ca}^{2+}\right]_{\mathrm{i}}$ in smooth muscle cells and relax the aortic rings.

In smooth muscle cells, $\mathrm{K}^{+}$channels play an important role in the control and regulation of membrane potential and vascular tone (Karaki and Weiss, 1984; Brayden, 1996). The activity of $\mathrm{K}^{+}$channels is regulated by electrochemical gradient for $\mathrm{K}^{+}$ions and the increase of external $\mathrm{K}^{+}$ concentration prevents $\mathrm{K}^{+}$efflux which leads to membrane hyperpolarization and subsequent reduction in $\left[\mathrm{Ca}^{2+}\right]_{\mathrm{i}}$ and vasorelaxation (Jackson, 2005). In our experiments on aortic rings precontracted with various concentrations of $\mathrm{KCl}(20-80 \mathrm{mM})$, it was found that 1-O-BN induced a more potent vasorelaxation in the aortic rings pre-contracted by low $\mathrm{KCl}(20 \mathrm{mM})$. This finding suggests that vasorelaxation induced by 1-O-BN might be associated with activation of $\mathrm{K}^{+}$efflux which leads to hyperpolarization of the smooth muscle cell membrane and subsequent inhibition of $\mathrm{Ca}^{2+}$ influx and vasorelaxation. 
To identify the specific types of $\mathrm{K}^{+}$channels involved in the vasorelaxant action of 1-O-BN its effects were examined in the presence of different blockers of these channels including TEA, 4$\mathrm{AP}, \mathrm{BaCl}_{2}$, and glibenclamide. In these experiments, it was found that of all used blockers only glibenclamide, a $\mathrm{K}_{\mathrm{ATP}}$ channels blocker, more markedly reduced the vasorelaxant effect of 1-O$\mathrm{BN}$. In contrast, other used $\mathrm{K}^{+}$channels blockers, including TEA, 4-AP and $\mathrm{BaCl}_{2}$ not significantly attenuated the vasorelaxant effect of 1-O-BN. These results suggest that activation of $\mathrm{K}_{\mathrm{ATP}}$ channels possible involved in vasorelaxation produced by 1-O-BN. To confirm this further, the effects of glibenclamide on vasorelaxation induced by 1-O-BN and the $\mathrm{K}_{\text {ATP }}$ channels opener nicorandil were compared. These experiments showed that in aortic rings precontracted with $20 \mathrm{mM} \mathrm{KCl}$ nicorandil and 1-O-BN induced vasorelaxation in a similar concentration-dependent manner and with almost the same potency. Furthermore, pretreatment of aortic rings with glibenclamide $(50 \mu \mathrm{M})$ shifted the concentration-response curve for nicorandil and 1-O-BN to the right in a parallel manner and reduced the maximum of vasorelaxation induced by these agents with almost equal effectiveness. These results together strongly suggest that activation of $\mathrm{K}_{\mathrm{ATP}}$ channels plays an important role in 1-O-BN produced vasorelaxation.

\section{CONCLUSIONS}

The present study provides the first evidence that 1-O-benzoylnappeline produced vasorelaxation in the rat aortic rings via multiple mechanisms, which possible involves the inhibition of $\mathrm{Ca}^{2+}$ influx through sarcolemmal voltage-dependent $\mathrm{Ca}^{2+}$ channels, $\mathrm{Ca}^{2+}$ release from intracellular stores and activation of $\mathrm{K}_{\mathrm{ATP}}$ channels. The finding that 1-O-BN is able to activate the $\mathrm{K}_{\mathrm{ATP}}$ channel which plays a critical role in vascular tone regulation and contributes to the pathogenesis of many vascular diseases may help to develop new effective approaches for therapy these diseases.

\section{Acknowledgments}

This work was supported by a grant FA-F6-T083 from the Coordinating Committee for Development of Science and Technology under the Cabinet of Ministers of the Republic of Uzbekistan.

\section{REFERENCES}

[1] Begdullaeva, G.S., Esimbetov, A.T., Usmanov, P.B., Sultankhodjaev, M.N. (2011). Effect of 1-0- benzoylnapelline on the contractile activity of rat trachea. Uzbek Biol. J. 3: 21-24.

[2] Berridge, M.J. (1997). Elementary and global aspects of calcium signaling. J Physiol. 499: 291-306.

[3] Brayden, J.E. (1996). Potassium channels in vascular smooth muscle. Clin. Exp. Pharmacol. 23: 1069-1076.

[4] Cribbs, L.L. (2001). Vascular smooth muscle calcium channels. Circulation Research. 89: 560-562.

[5] Dzhakhangirov, F.N., Kasymova, K.R., Sultankhodzhaev, M.N., Salimov, B.T., Usmanova, S.K., Shakirov, R.Sh. (2007). Toxicity and local anesthetic activity of diterpenoid alkaloids. Chemistry of Natural Compounds. 43: 581-589. 
[6] Dzhakhangirov, F.N., Tursunkhodzhaeva, F.M., Sultankhodzhaev, M.N., Salimov, B.T. (2013). Spasmolytic activity of diterpenoid alkaloids and their derivatives. Structureactivity relationship. Chemistry of Natural Compounds. 49: 702-706.

[7] Guzman, E., and Molina, J. (2018). The predictive utility of the plant phylogeny in identifying sources of cardiovascular drugs. Pharmaceutical Biology. 56 (1): 154-164.

[8] Jackson, W.F. (2005). Potassium channels in the peripheral microcirculation. Microcirculation. 12(1): 113127.

[9] Karaki, H., and Weiss, G. (1984). Calcium channels in smooth muscle. Gastroenterology. 87: 960-970.

[10]Lee, R. (2001). Functional Genomics and Cardiovascular Drug Discovery. Circulation Research. 104: 1441-1446.

[11]Li, X., Li, N., Sui, Z., Bi, K., Li, Z. (2017). An Investigation on the quantitative structureactivity relationships of the anti-inflammatory activity of diterpenoid alkaloids. Molecules. 27: $22-23$.

[12] Nelson, M.T., and Quayle, J.M. (1995). Physiological roles and properties of potassium channels in arterial smooth muscle. Am. J. Physiol. 268 (37): 799-822.

[13] Pereira, F. (2017). Polypharmacology of Aconitum and Delphinium sp. Diterpene Alkaloids: Antiarrhythmic, Analgesic and Anti-Inflammatory Effects. Mini-Reviews in Organic Chemistry. 14: 1-7.

[14] Sanders, K.M. (2001). Invited review: Mechanisms of calcium handling in smooth muscles. J Appl Physiol. 91: 1438-1449.

[15] Tabassum, N., and Ahmad, F. (2011). Role of natural herbs in the treatment of hypertension. Pharmacogn Rev. 5(9): 30-40.

[16] Tirapelli, C.R., Ambrosio, S.R., de Oliveira, A.M., Tostes, R. (2010). Hypotensive action of naturally occurring diterpenes: A therapeutic promise for the treatment of hypertension. Fitoterapia. 81 (I7): 690-702.

[17] Wray, S., and Burdiga T. (2010). Sarcoplasmic Reticulum Function in Smooth Muscle. Physiol Rev. 90: 113-178. 